\title{
Betonun Mekanik Özelliklerinin Çarpma Dayanımına Etkisi
}

\author{
The effect of mechanical properties of concrete on impact strength
}

\author{
Kürşat KAYMAZ ${ }^{* 1, a}$, Erdinç ARICI ${ }^{2, b}$ \\ ${ }^{I}$ Munzur Üniversitesi, Mühendislik Fakültesi, İnşaat Mühendisliği Bölümü, Tunceli, Türkiye \\ ${ }^{2}$ Fırat Üniversitesi, Teknoloji Fakültesi, İnşaat Mühendisliği Bölümü, Elazığ, Türkiye
}

\begin{abstract}
• Geliş tarihi / Received: 27.06.2018 • Düzeltilerek geliş tarihi / Received in revised form: 03.11.2018 • Kabul tarihi / Accepted: 07.11.2018
Öz

Bu çalışmada; betonun mekanik özelliklerinden olan basınç, eğilmede çekme ve yarmada çekme dayanımlarının çarpma dayanımı üzerindeki etkileri incelenmiştir. Bu amaç doğrultusunda maksimum agrega çapı 4,8 ve $16 \mathrm{~mm}$, su/çimento $(\mathrm{S} / \mathrm{C})$ oranı ise 0.50 ve 0.55 olan altı seri numuneleri hazırlanmıştır. Hazırlanan numuneler üzerinde basınç, eğilme, yarma ve Charpy darbe dayanımları belirlenmiştir. Yapılan deneysel çalışmalar sonucunda; betonun mekanik özelliklerini agrega çapındaki artış olumlu etkilerken S/Ç oranındaki artış olumsuz yönde etkilemiştir. Betonun çarpma dayanımındaki değişim de aynı şekilde olmuştur. Fakat çarpma dayanımı $\mathrm{S} / C ̧$ oranındaki artıştan daha az etkilenmiştir.
\end{abstract}

Anahtar kelimeler: Basınç Dayanımı, Beton, Charpy Deneyi, Çarpma Dayanımı, Çekme Dayanımı.

\begin{abstract}
In this study, impact stregth of concrete is investigated with the effect of mechanical properties such as compressive strength, flexural tensile strength and splitting tensile strength. For this purpose, six serial specimens with three different maximum aggregate diameter $(4,8$ and $16 \mathrm{~mm})$ and whose water/cement $(w / c)$ ratio of 0.50 to 0.55 were prepared. The compressive, bending, splitting and impact strength of the prepared specimens were determined. As a result of study; The mechanical properties of the concrete were positively effected by the increase in the aggregate size, while the icrease in the W/C ratio adversely effected. The change in the impact strength of concrete has also been the same. But the impact strength is less effected than the increase in W/C ratio.
\end{abstract}

Keywords: Compressive Strength, Concrete, Charpy Experiment, Impact Strength, Tensile Strength.

\footnotetext{
*a Kürşat KAYMAZ; kkyamaz@munzur.edu.tr ; Tel: 0 (4248) 21317 94; orcid.org/ 0000-0002-8346-8260

${ }^{\mathrm{b}}$ orcid.org/0000-0002-6153-5805
} 


\section{Giriş}

Değişik türdeki yapılarda kullanılmakta olan betonun üzerine değişik yönlerde etki yapan statik veya dinamik yükler gelebilmektedir. Beton, bu yükleri taşıyabilmek için direnç göstermektedir. Doğal olarak, üzerine gelen yükün etkisiyle betonda bir miktar şekil değişikliği meydana gelmektedir. Üzerine gelen yüklerin büyüklüğü arttıkça, hem betondaki şekil değişikliğinin miktarı artmakta, hem de bu yükleri taşıyabilmek için daha çok direnç gerekmektedir. Eğer meydana gelen yükleme betonun taşıma kapasitesinden daha fazla boyutlarda oluşursa, betonda şekil değişikliğiyle birlikte betonun kırılmasına neden olmaktadır (Mather, B., 1994). Betonun üzerine değişik yönlerde uygulanan yükler, değişik etkiler yaratabilmektedir. Basınç, çekme, eğilme ve kayma etkisi yaratacak yükler altında betonun şekil değiştirmeye ve kırılmaya karşı göstereceği direnme kabiliyeti sırasıyla; basınç dayanımı, çekme dayanımı, eğilme dayanımı, kayma dayanımıdır (Erdoğan, 2003). Özellikleri en az bilinen ve incelenmiş yüklemelerden biri de çarpma yüklemesidir (Murtiadi, 1999). Çarpma yüklemesinde anlık yüksek değerlerdeki şiddet etkiyle meydana gelen gerilmeler diğer yükleme değerine göre daha fazladır. Çarpma sonucu oluşan dinamik etki, statik yüklemelere göre yapıda yüksek oranlarda ani gerilme artışları meydana getirmektedir. $\mathrm{Bu}$ gerilme artışları yapı elemanlarında anlık çatlamalara sebep olarak yap1 güvenliğini olumsuz yönde etkilemektedir. Çarpma kuvvetlerinin oluşturduğu gerilmelerin yap1 elemanları üzerindeki etkileri belirleyecek kesin bir yöntem olamaması ise bu konu üzerinde yapılan çalışmaların en büyük sorunudur. Kullanım amaçlarına göre beton ve betonarme yapı elemanları çarpma etkisi altında kalabilirler. Örneğin birçok beton ve betonarme yapılardan; döşeme kaplamaları, hava alanları, yollar, kazık ve palplanş başlıkları çarpma tesirine maruz kalabilmektedir. Bir malzeme üzerinde çarpma etkisi, yüzeyine bir cismin belirli yükseklikten düşmesi yolu ile olacağı gibi aniden uygulanan kuvvetler şeklinde de olabilir. Çarpma sonucunda bir cisimde gerilmeler çok kısa sürede büyük değerlere ulaşabilmekte, gerilme ve deformasyonlar karmaşık hale geldiği için teorik olarak irdelemesi zor olmaktadır. (Arıcı vd., 2007). Teknolojik gelişmelerle birlikte çelik ve beton gibi temel yap1 malzemelerinin çarpma yükleri altında gösterdikleri davranış biçimi daha da önem kazanmıştır. Örneğin nükleer santrallerde reaksiyonlar sırasında ortaya çıkan yükler kısa sürede çok büyük değerlere ulaşabilmektedir (Kantar vd., 2011). Çarpma deneyleri yakın tarihimize kadar temel yapı malzemelerinden olan çelik üzerinde yoğunlaşmıştır. Fakat betonun aktif kullanımı yaygınlaştıkça, çarpma etkisi altında davranışı önem kazanmaya başlamıştır. Bu güne kadar yapılan çalışmalarda deney metotları ve prosedür hakkında herhangi bir standart oluşturulamamıştır (Arıcı vd., 2007; Selvi, 2008). Çarpma deneyleri, malzeme şekline ve cinsine bağlı olarak farklı şekillerde yapılabilmektedir. Bunlar;

a. Hareketli Sarkaç - Charpy (Edgington vd., 1974; Johnston, 1974) İzod (Arıc1, E., 2010).

b. Düşen Top - Düşme makinesinin farklı tipleri ise sabit yükseltideki düşüş veya değişken yükseltideki düşüş (Verhagen, 1978; Jamrozy vd., 1979).

c. Kesin bir yükseklikten düşürülen yapısal elemanlar (Barb vd., 1974).

d. Patlayıc1 Maddeler (Verhagen, 1978; Jamrozy vd., 1979; Williamson, G. R., 1965) 'dir.

Malzemelerin çarpma dayanım değerlerini tespiti etmek amaciyla malzemenin cinsine göre farklı deney metotlarını içeren standartlar mevcuttur. Çarpma dayanımının belirlenmesine yönelik son zamanlarda farklı çalışmalarda Charpy darbe deneyi üzerinde araştırmalar yapılmıştır (Arıcı, 2010). Darbe testinde dinamik bir yüklemeyle numunelerin kırılması için gerekli enerji belirlenir. Bu enerji miktarlar1 numunelerin kesit alanına bölünerek darbe direnci değeri olarak çarpma dayanımını elde edilmektedir. Enerjinin korunumunun temel prensibindeki Charpy düzeneğinde; sarkaca belli bir yükseklikte enerji kazandırılır, sarkaç serbest bırakıldığında enerjinin bir kısmı numuneyi kırmada harcanırken geri kalanı ile sarkaç bir miktar daha yükselir. Şekil 1'deki Charpy deney düzeneğinde ağırlığı G olan sarkaç, $\mathrm{h}_{0}$ yüksekliğinde potansiyel enerjisi $\left(\mathrm{Gxh}_{0}\right)$ yükseklikte maximum düzeydedir. Sarkaç bu yükseklikten serbest bırakıldığında, düşey bir dogrultuda salınarak numuneyi kırma işleminden sonra bir h yüksekliğine çıkmaktadır. Böylece bu kırılma işlemi sonrasındaki sarkaçta kalan potansiyel enerji (Gxh) yüksekliğindedir. Şekil 1'de gösterilen Charpy deney düzeneğinde enerjinin korunumu kanununda faydalanılarak hesaplamalar yapılmaktadır. 

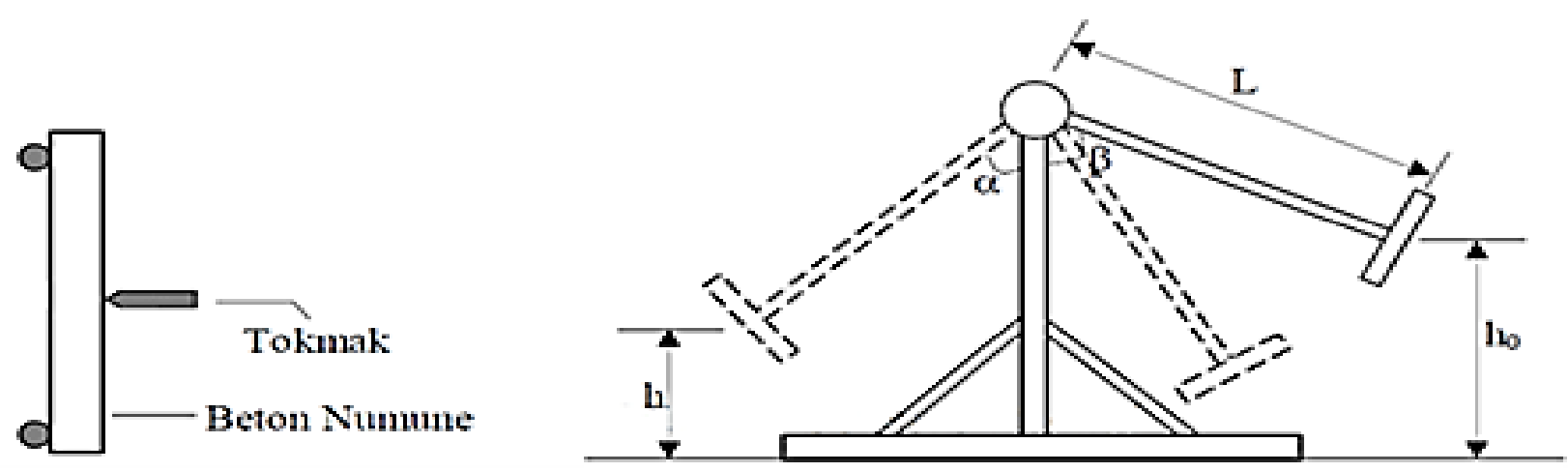

Şekil 1. Charpy Deney Düzeneği

Numunenin kırılmasında, sarkaçtaki tokmağın numune ile temas ettiği noktadaki enerjisi ile numunenin kırılma sonrasındaki sarkaçta kalan potansiyel enerjisi fark1 o numunenin kırılmas1 için gerekli enerjiyi göstermektedir. Bu formülle şu şekilde gösterilebilir.

$U=G\left(h_{0}-h\right)=G L(\cos \beta-\cos \alpha)$

Burada, sarkaç tokmağının ilk ve son konum noktalarındaki potansiyel enerji farklarından elde edilen değerler bulunur ve bu değerler numunenin kesit alanları da hesaba katılarak çarpma mukavemeti formülle elde edilir.

$C_{C}=\frac{U}{A}=\frac{G\left(h_{0}-h\right)}{A}$

\section{Materyal ve Metot}

Deneylerde kullanılan agrega, Elazığ ili, Palu ilçesinden temin edilmiştir. Mineralojik olarak nehir kumu niteliğinde olan agreganın özellikleri Tablo 1'de verilmiştir. Çimento olarak; Tablo 2'deki fiziksel ve kimyasal özelliği verilen Ergani Çimento Sanayi T.A.Ş 'nin üretimindeki CEM IV 32.5 R tipi kullanılmıştır. Deney numuneleri TS 802' ye göre hazırlanmış (Williamson, 1965) ve Tablo 3'de bu veriler gösterilmiştir. Numunelerin seri özeliklerine göre, maksimum dane çapları 4,8 ve $16 \mathrm{~mm}$ olarak alınmıştır. Granülometrik bir karışım oluşturulması amacıyla TS 706'daki sınır değerlere uygun olarak ayarlanmıştır.

Tablo 1. Karışıma giren agregaya ait genel özellikler

\begin{tabular}{lllllll}
\hline $\begin{array}{l}\text { Özgül } \\
\left(\mathrm{gr} / \mathrm{cm}^{3}\right)\end{array}$ & ağırlık & $\begin{array}{l}\text { Su } \\
(\%)\end{array}$ & $\begin{array}{l}\text { Aşımma kayb1 } \\
(\%)\end{array}$ & $\begin{array}{l}\text { Kil miktarı } \\
(\%)\end{array}$ & $\begin{array}{l}\text { Donma kayb1 } \\
(\%)\end{array}$ \\
\hline 2.48 & 4 & 16.6 & 2.0 & 1.83 \\
\hline
\end{tabular}

Tablo 2. CEM IV 32.5 R Tipi çimentonun fiziksel ve kimyasal analizleri

\begin{tabular}{llllllll}
\hline $\mathrm{SiO}_{2}$ & $\mathrm{Al}_{2} \mathrm{O}_{3}$ & & $\mathrm{Fe}_{2} \mathrm{O}_{3}$ & $\mathrm{CaO}$ & $\mathrm{MgO}$ & $\mathrm{SO}_{3}$ \\
\hline 26.86 & 8.09 & & 5.18 & 45.88 & & 3.64 & 2.41 \\
\hline \hline $45 \mu$ & Blaine & Priz b. & Priz s. & Öz. ağ. & Yoğunluk & H. gen. & 2 gün \\
\hline 1.9 & 4326 & 2.35 & 3.45 & 2.98 & 925 & 4 & 16.9 \\
\hline
\end{tabular}

Serilerin karışım hesaplamalarında, max. agrega çap1 4,8 ve $16 \mathrm{~mm}$., $\mathrm{S} / \mathrm{C}$ (su/çimento) oranı ise 0.50 ve 0.55 olarak alınmıştır. 
Tablo 3. Karışıma giren malzeme miktarları

\begin{tabular}{|c|c|c|c|c|c|c|}
\hline \multirow{2}{*}{$\begin{array}{l}D_{\text {max }} \\
(\mathbf{m m})\end{array}$} & \multirow{2}{*}{$\mathbf{S} / \mathbf{C}$} & \multirow{2}{*}{$\begin{array}{l}\text { Çimento } \\
\text { (kg) }\end{array}$} & \multirow{2}{*}{$\underset{(\mathrm{Sg})}{\mathrm{Su}}$} & \multicolumn{3}{|c|}{$\begin{array}{l}\text { Agrega } \\
(\mathbf{m m})\end{array}$} \\
\hline & & & & $0-4$ & $4-8$ & $8-16$ \\
\hline \multirow{2}{*}{4} & $\begin{array}{l}0.50 \\
\text { (Seri 1) }\end{array}$ & 400 & 200 & 1564 & - & - \\
\hline & $\begin{array}{l}0.55 \\
\text { (Seri 2) }\end{array}$ & 357 & 197 & 1609 & - & - \\
\hline \multirow{2}{*}{8} & $\begin{array}{l}0.50 \\
\text { (Seri 3) }\end{array}$ & 380 & 190 & 1142 & 489 & - \\
\hline & $\begin{array}{l}0.55 \\
\text { (Seri 4) }\end{array}$ & 345 & 190 & 1162 & 498 & - \\
\hline \multirow{2}{*}{16} & $\begin{array}{l}0.50 \\
\text { (Seri 5) }\end{array}$ & 334 & 167 & 963 & 350 & 437 \\
\hline & $\begin{array}{l}0.55 \\
\text { (Seri 6) }\end{array}$ & 304 & 167 & 976 & 355 & 443 \\
\hline
\end{tabular}

Basınç deneyleri 150x300 mm. lik silindir numunelerle, eğilmede çekme deneyleri 100x100x500 mm. lik kiriş numunelerde, yarma deneyleri 100x200 mm. lik silindir numunelerde ve Charpy darbe deneyleri ise 100x100x500 mm. lik numunelerde yapılmıştır. Betonun mekanik özellikleri ile çarpma dayanımları arasındaki ilişkinin belirlenmesi amacıyla, çarpma dayanım değerleri sırasıyla basınç dayanımının karekökü, eğilmede çekme dayanımı ve yarmada çekme dayanımları ile bölünerek “q” değeri elde edilmiştir.

$q=\frac{C}{\sqrt{\sigma}}$

Ayrıca $\mathrm{D}_{\max }$ (max. agrega çapı) ve S/Ç (su / çimento) oranlarına bağlı olarak dayanım değerlerindeki değişim oranları hesaplanmıştır. Aşağıda Tablo 4 ve Tablo 5'de bu değerler gösterilmektedir.

Tablo 4. Serilerin dayanım değerleri

\begin{tabular}{|c|c|c|c|c|c|c|c|}
\hline $\begin{array}{l}\text { Seri } \\
\text { No }\end{array}$ & $\begin{array}{l}\text { Çarpma } \\
\text { Dayanımı } \\
\text { (Ç) } \\
\text { (N.mm) }\end{array}$ & $\begin{array}{l}\text { Basınç } \\
\text { Dayanımı } \\
(\sigma)\left(\mathrm{N} / \mathbf{m m}^{2}\right)\end{array}$ & $\begin{array}{l}\mathbf{q}_{\sigma} \\
(C ̧ / \sqrt{ } \sigma)\end{array}$ & $\begin{array}{l}\text { Eğilmede } \\
\text { Çekme } \\
\text { Dayanımı } \\
\left(\sigma_{E}\right) \\
\left(\mathrm{N} / \mathbf{m m}^{2}\right)\end{array}$ & $\begin{array}{l}\mathbf{q}_{\sigma \mathrm{E}} \\
\left(C \zeta / \sigma_{\mathrm{E}}\right)\end{array}$ & $\begin{array}{l}\text { Yarma } \\
\text { Dayanımı } \\
\left(\sigma_{\mathrm{c}}\right) \\
\left(\mathrm{N} / \mathbf{m m}^{2}\right)\end{array}$ & $\begin{array}{l}\mathbf{q}_{\sigma \boldsymbol{c}} \\
\left(C \zeta / \sigma_{C}\right)\end{array}$ \\
\hline S1 & 3.84 & 25.49 & 0.76 & 4.41 & 0.87 & 3.50 & 1.10 \\
\hline S2 & 3.65 & 20.63 & 0.80 & 3.39 & 1.08 & 2.79 & 1.31 \\
\hline S3 & 4.10 & 27.11 & 0.79 & 4.78 & 0.86 & 3.94 & 1.04 \\
\hline S4 & 3.92 & 23.48 & 0.80 & 4.55 & 0.97 & 3.09 & 1.25 \\
\hline S5 & 4.69 & 31.86 & 0.83 & 5.34 & 0.88 & 4.35 & 1.08 \\
\hline S6 & 4.49 & 28.84 & 0.84 & 4.64 & 0.97 & 3.47 & 1.30 \\
\hline
\end{tabular}


Tablo 5. Agrega çapı ve S/Ç oranına göre dayanımlarındaki azalma yüzdeleri

\begin{tabular}{|c|c|c|c|c|c|c|c|c|c|}
\hline \multirow{2}{*}{$\mathbf{D}_{\max }$} & \multirow[t]{2}{*}{$\mathbf{S} / \mathbf{C}$} & \multicolumn{2}{|c|}{ Basınç Dayanımı } & \multicolumn{2}{|c|}{$\begin{array}{l}\text { Eğilme } \\
\text { Dayanımı }\end{array}$} & \multicolumn{2}{|c|}{$\begin{array}{l}\text { Yarma } \\
\text { Dayanımı }\end{array}$} & \multicolumn{2}{|c|}{$\begin{array}{l}\text { Çarpma } \\
\text { Dayanımı }\end{array}$} \\
\hline & & $\mathbf{N} / \mathbf{m m}^{2}$ & $\%$ & $\mathrm{~N} / \mathrm{mm}^{2}$ & $\%$ & $\mathrm{~N} / \mathrm{mm}^{2}$ & $\%$ & $\mathrm{~N} / \mathrm{mm}^{2}$ & $\%$ \\
\hline 4 & $\begin{array}{l}0.50 \\
0.55\end{array}$ & $\begin{array}{l}25.49 \\
20.63\end{array}$ & 23.56 & $\begin{array}{l}4.41 \\
3.39\end{array}$ & 30.09 & $\begin{array}{l}3.50 \\
2.79\end{array}$ & 25.45 & $\begin{array}{l}3.84 \\
3.65\end{array}$ & 5.21 \\
\hline 8 & $\begin{array}{l}0.50 \\
0.55 \\
\end{array}$ & $\begin{array}{l}27.11 \\
23.48 \\
\end{array}$ & 15.46 & $\begin{array}{l}4.78 \\
4.01 \\
\end{array}$ & 19.20 & $\begin{array}{l}3.94 \\
3.09 \\
\end{array}$ & 27.51 & $\begin{array}{l}4.10 \\
3.88 \\
\end{array}$ & 5.67 \\
\hline 16 & $\begin{array}{l}0.50 \\
0.55\end{array}$ & $\begin{array}{l}31.86 \\
28.84\end{array}$ & 10.47 & $\begin{array}{l}5.34 \\
4.64\end{array}$ & 15.09 & $\begin{array}{l}.35 \\
3.47\end{array}$ & 25.36 & $\begin{array}{l}4.69 \\
4.49\end{array}$ & 4.45 \\
\hline
\end{tabular}

\section{Sonuç ve Öneriler}

Yapılan deneysel çalışmalardan elde edilen sonuçlar şunlardır.

a) Basınç dayanımı, eğilmede çekme ve yarmada çekme dayanımı değerleri agrega çapının büyümesine bağlı olarak artmıştır. $\mathrm{Bu}$ artış çarpma dayanımını da olumlu yönde etkilemiştir.

b) $\mathrm{S} / C ̧$ oranının artışı ile basınç, eğilmede çekme, yarmada çekme ve çarpma dayanımları azalmıştır.

c) $\mathrm{S} / \mathrm{C}$ oranındaki artış; basınç, eğilmede çekme ve yarmada çekme dayanımlarında aşırı derecede bir düşüşe sebep olurken, çarpma dayanımındaki düşme oranı $\% 5$ gibi küçük bir değerde kalmıştır.

d) $\mathrm{S} / \mathrm{C}$ oranı ve agrega çapındaki değişimle beraber dayanım değerlerindeki \% değişimlerine bakıldığında; basınç ve eğilmede çekme dayanımlarında değişim geniş bir aralıkta olmasına karşın yarmada çekme dayanımı ve çarpma dayanım değişimleri ortalama olarak aynı değerlerde (\% 25 ve \% 5) kalmıştır.

e) Çarpma dayanımı hesaplandıktan sonra çekme dayanımı ile arasındaki ilişkinin belirlenmesi amacıyla çarpma dayanımı ile çekme dayanımı arasındaki oran (q) hesaplanmıştır. Bu değerlerden görüleceği üzere $d_{\max }$ değerinin büyümesiyle beraber $\mathrm{q}$ değerinde de artış olmuştur. Aynı şekilde S/Ç oranının artması ile beraber q değerindeki artış devam etmiştir. Bunun sebebi S/Ç oranındaki artış, basınç, eğilme ve yarma dayanımlarını çok fazla düşürmesine karşın, çarpma dayanımındaki düşme miktarının daha küçük olmasıdır.

Charpy düzeneğinde deney esnasında bir miktar hesapta olmayan enerji kayb1 meydana gelmektedir, bu kayıp deney sonuçlarına etki etmektedir. Fakat bütün deneyler aynı şartlar altında yapıldığından ve bu enerji kaybı değeri çok küçük olduğundan dolayı ihmal edilmiştir. Daha sağlıklı sonuçların elde edilmesi için, bu kayıp oranlarının tam olarak belirlenip, sonuç üzerinde etki ettirilmesi daha uygun olacaktır. Ayrıca yarma dayanımı ile çarpma dayanımı arasındaki ilişkinin daha net incelenmesi yararlı olacaktır.

\section{Kaynaklar}

Arıc1, E., Dursun, R. ve İnce, R., 2007. Determination of Impact Strength of Concrete. 8th International Fracture Conference, November 2007, İstanbul, Turkey, 628-633.

Arıc1, E., 2010. Effect of Compressive Strength on Impact Strength of Concrete. Journal of Technical, 9 (1), 1-9.

Barb, S., Hanson, D., 1974. Investigation of Fiber Reinforced Breakwater Armour Units. Fiber Reinforced Concrete Publication SP44, American Concrete Institute, Detroit, $434 \mathrm{p}$.

Edgington, J., Hannant, D. J. ve Williams, G.I.T., 1974. Steel Fibre Reinforced Concrete. Building Research Establishment Current Paper, The Establishment, 46p.

Erdoğan, T.Y., 2003. Beton. ODTÜ Geliştirme Vakfı Yayıncılık ve İletişim A.Ş Yayınları, Ankara, 446p.

Jamrozy, Z. ve Swamy, R.N., 1979. Use of Steel Fibre Reinforcement for Impact Resistance and Machinery Foundations. International Journal of Cement Composites, 1 (2), 6575 .

Johnston, C. D., 1974. Steel Fiber Reinforced Mortar and Concrete. A Review of Mechanical Properties Fiber Reinforced Concrete, Publication SP-44, American Concrete Institute.Detroit, 127-142. 
Kantar, E., Arslan, A. ve An1l, Ö., 2011. Effect of Concrete Compressive Strength Variation on Impact Behaviour. Engineering Architecture Faculty journal Gazi University, 26 (1), 115-123.

Mather, B., 1994. Cement and Concrete Terminology. American Concrete Institute, 116 (R-90), 1-68.

Murtiadi, S., 1999. Behavior of High-Strength Concrete Plates under Impact Loading. Master Thesis, Faculty of Engineering and Applied Science Mernorial University of Newfoundland, 17p.

Selvi, M., 2008. Beton Dayanımındaki Değişimin Çarpma Dayanımına Olan Etkisinin
Deneysel ve Sonlu Elemanlar Yöntemiyle İncelenmesi. Yüksek Lisans Tezi, Gazi Üniversitesi Fen Bilimleri Enstitüsü. Ankara,119 s.

Verhagen, A. H., 1978. Impact Testing of Fibre Reinforced Concrete: Reflection on Possible Test Methods, Testing and Test Methods of Fibre Cement Composites RILEM Symposium Edited by R. N. Swamy, The Construction Press Ltd., Hornby, p.99-105.

Williamson, G. R., 1965. Fibrous Reinforcements for Portland Cement Concrete. Technical Report. 1, 1-500. 